\title{
Structured and shared CT radiological report of gastric cancer: a consensus proposal by the Italian Research Group for Gastric Cancer (GIRCG) and the Italian Society of Medical and Interventional Radiology (SIRM)
}

\author{
Maria Antonietta Mazzei ${ }^{1,2} \cdot$ Giulio Bagnacci $^{1,2} \cdot$ Francesco Gentili $^{2,3}$ (D) $\cdot$ lacopo Capitoni ${ }^{1} \cdot$ Gianni Mura $^{4}$. \\ Daniele Marrelli ${ }^{5}$. Roberto Petrioli ${ }^{6}$. Luca Brunese ${ }^{7,8}$. Salvatore Cappabianca ${ }^{9,8}$ - Marco Catarci ${ }^{10}$. \\ Maurizio Degiuli ${ }^{11}$. Giovanni De Manzoni ${ }^{12}$. Marco De Prizio ${ }^{4}$. Annibale Donini ${ }^{13}$. Uberto Fumagalli Romario ${ }^{14}$. \\ Luigi Funicelli $^{14,2,8}$. Andrea Laghi ${ }^{15,16}$. Giuseppe Minetti ${ }^{17,2} \cdot$ Paolo Morgagni $^{18}$ - Enrico Petrella ${ }^{19} \cdot$ Frida Pittiani $^{20,2}$. \\ Stefano Rausei ${ }^{21}$ - Laura Romanini ${ }^{22}$ - Riccardo Rosati ${ }^{23}$ - Amato Antonio Stabile lanora ${ }^{24}$. Guido A. M. Tiberio ${ }^{25}$. \\ Luca Volterrani $^{1,8} \cdot$ Franco Roviello $^{5} \cdot$ Roberto Grassi $^{9,26}$
}

Received: 26 April 2021 / Revised: 15 June 2021 / Accepted: 7 July 2021 / Published online: 12 August 2021

(C) European Society of Radiology 2021

\begin{abstract} Delphi survey, to develop a structured reporting template for CT of GC patients. follow-up). stability $(p>0.05)$. useful for multidisciplinary decision-making.

Key Points

- Imaging represents the cornerstone for tailored treatment in GC patients.

- CT-structured radiology report in GC patients is useful for multidisciplinary decision making.
\end{abstract}

Objectives Written radiological report remains the most important means of communication between radiologist and referring medical/surgical doctor, even though CT reports are frequently just descriptive, unclear, and unstructured. The Italian Society of Medical and Interventional Radiology (SIRM) and the Italian Research Group for Gastric Cancer (GIRCG) promoted a critical shared discussion between 10 skilled radiologists and 10 surgical oncologists, by means of multi-round consensus-building

Methods Twenty-four items were organized according to the broad categories of a structured report as suggested by the European Society of Radiology (clinical referral, technique, findings, conclusion, and advice) and grouped into three " $\mathrm{CT}$ report sections" depending on the diagnostic phase of the radiological assessment for the oncologic patient (staging, restaging, and

Results In the final round, 23 out of 24 items obtained agreement $(\geq 8)$ and consensus $(\leq 2)$ and 19 out 24 items obtained a good

Conclusions The structured report obtained, shared by surgical and medical oncologists and radiologists, allows an appropriate, clearer, and focused CT report essential to high-quality patient care in GC, avoiding the exclusion of key radiological information

Keywords CT scan $\cdot$ Stomach neoplasms $\cdot$ Report

\author{
Abbreviations \\ GC Gastric cancer \\ MDT Multidisciplinary team \\ PC Peritoneal carcinomatosis
}

Francesco Gentili

francescogentili@gmail.com

Extended author information available on the last page of the article

\section{Introduction/background}

Gastric cancer (GC) is an aggressive tumor and it remains the third cause of mortality for cancer worldwide [1].

Even if The Cancer Genome Atlas (TCGA) has recently allowed a comprehensive molecular characterization of GC, 
heralding what could be eventual targets for future targetoriented therapy, at present, the therapeutic options and the prognosis of GC patients are still related to the tumor stage and to the modality of the spread of the disease $[2,3]$.

Endoscopic therapy, surgery, systemic chemotherapy, target therapy, radiotherapy, and loco-regional treatments are available with multimodal and multidisciplinary approaches according to the stage and the phase of the disease [4-6].

In particular, endoscopic mucosal resection/submucosal dissection is the preferred approach in very early, superficial cancers (T1a), whereas, in the early-stage cancers not suitable for endoscopic resection, surgical resection is considered the treatment of choice [7].

Total/distal gastrectomy (depending on the site of the tumor), plus regional D2 lymph-nodal dissection, associated with neoadjuvant chemotherapy, represents the standard treatment for locally advanced $\mathrm{GC}$ ( $\geq \mathrm{T} 3$, any $\mathrm{N}$ or $\geq \mathrm{T} 2, \mathrm{~N}+$ ) in Western countries [8-13]. Neoadjuvant therapy (either preoperative or peri-operative) can improve the R0 surgical resection rate, reduce distant metastasis and recurrence rate, and improve survival of patients by tumor downstaging $[1,8,14$, $15]$.

In advanced unresectable/metastatic GC (35-40\% of cases at the time of the first diagnosis), chemotherapy is still considered the standard treatment $[1,16]$. In the last decade, the use of locoregional treatment is also increasing: in selected cases with peritoneal carcinomatosis (PC), radical gastrectomy associated with cytoreductive surgery and intraperitoneal hyperthermic chemotherapy (HIPEC) can be performed, with significant advantages in overall survival and peritoneal recurrence rates [17, 18]. Furthermore, the introduction of new anticancer agents and the development of polychemotherapy regimens have made macroscopic complete curative resection possible in some patients with metastatic or unresectable GC before therapy. This type of surgery, known as "conversion" surgery, is defined as a surgical treatment with the goal of R0 resection in initially unresectable $\mathrm{GC}$ patients after response to chemotherapy [19-21].

It is therefore crucial to correctly define the clinical stage of the disease and the pathway of dissemination (lymph-nodal, hepatic, peritoneal), including the distribution and the burden of the disease, in order to choose the most effective therapeutic path (up-front surgery versus chemotherapy treatment, whether it is for neoadjuvant, palliative, or conversion purposes), thus strongly impacting the prognosis of such patients. Furthermore, it is important to assess the response to neoadjuvant chemotherapy for properly choosing the timing of surgery, as well as the response to chemotherapy in metastatic or unresectable cancers to perform the conversion surgery.

The majority of the decision-making process reported above is largely driven by imaging and, in particular by CT that represents the workhorse in the imaging routine of GC patients $[22,23]$.
In this scenario and in the era of multidisciplinary and personalized medicine, the radiology report plays a key role to correctly address the flowchart of treatment and remains the main means of communication with clinicians; furthermore, the need for a uniform and standardized reporting scheme and language in imaging oncology has been welcomed by major scientific societies [24]. In the present study, the Italian Society of Medical and Interventional Radiology (SIRM) and the Italian Research Group for Gastric Cancer (GIRCG) have promoted a critical shared discussion between radiologists and clinicians (surgical oncologists), both experienced in GC, by means of multi-round consensus-building Delphi exercise, to develop a comprehensive focused structured reporting template for $\mathrm{CT}$ of patients with GC.

The objectives of the study were as follows: (1) the development of a comprehensive focused structured reporting template for CT of patients with GC (including those esophagogastric junction tumors redefined as gastric cancer in the $8^{\text {th }}$ edition of TNM [25]), taking into account the most relevant parameters according to the point of view of surgical oncologists and the assessment of the agreement among experts on the proposed criteria; (2) the standardization of the CT report for $\mathrm{GC}$ usable by the radiologist or the multidisciplinary team in a high-volume and reference centers for the treatment of GC; (3) the provision of a comprehensive and organized view of the $\mathrm{GC}$ report to radiology residents with educational purposes.

\section{Methods and materials}

\section{Writing committee}

Initially, a group of coordinators, composed of a radiologist (M.A.M.), a radiology resident (G.B.), and an internal student in radiology (I.C.), flanked by a statistician (F.F.), conducted a bibliographic search on various platforms about the Delphi method, structured reports, and CT for GC.

A four-member writing committee composed of a radiologist (M.A.M.), two surgical oncologists (G.M., D.M.), and an oncologist (R.P.), all with decades of experience in the diagnosis and treatment of GC, proposed a total of 24 "Delphi items". These items were organized according to the broad categories of the structured report as suggested by the European Society of Radiology [26] (clinical referral, technique, findings, conclusion, and advice) and grouped into three different "CT report sections" according to the "diagnostic phase" of the radiological assessment for the oncologic patient: (1) staging (CT exam performed at the time of the first diagnosis and before any treatment to obtain a clinical TNM, "cTNM"), 9 items; (2) restaging (CT exam performed after a non-radical therapy, including neoadjuvant therapy to obtain a y-clinical-TNM, "ycTNM"), 9 items; (3) follow-up (CT performed after a radical therapy), 6 items. Thus, tracing the new 
TNM staging edition that presents separate classifications applicable for therapeutic strategy: clinical staging cTNM (prior to any treatment), pathological staging pTNM (after upfront surgery), and neoadjuvant pathologic staging ypTNM (after neoadjuvant treatment followed by surgery) [25].

The 24 items were discussed by the writing committee both by e-mail and throughout in-person and telephone meeting, until a shared agreement was reached. Points inside single statements that did not reach a complete agreement were included as additional suggestions.

\section{Panel composition}

An "expert panel" was then set up. The adequate number of members of the expert panel for the purpose of the study was stated, in accordance with the literature [27], to be equal to 20 , evenly distributed between 10 radiologists and 10 surgical oncologists, recommended by the presidents of the SIRM and GIRCG (R.G. and F.R.), respectively. The invitations were individually e-mailed to the selected specialist, and anonymity was guaranteed for the entire Delphi process (during all three rounds). Adhesions received were 20 out of 20 experts, with a positive response rate of $100 \%$. The Delphi survey consisted of 3 different rounds. The writing committee members did not participate in the Delphi survey.

\section{Questionnaires and Delphi iterations}

Three rounds of questionnaires were sent out and the anonymous responses of the expert panel were aggregated and anonymously shared with the group by coordinators after each round as a feedback. The coordinators also fixed thresholds and goals to be obtained in order to reach an adequate consensus for the proposed items and to include additional suggestions into a statement in the following round (Table 1). Only the items that did not reach adequate consensus during a round have been reformulated according to free comments/additional suggestions proposed in the same round by the expert panel and then resubmitted for the vote in the next round.
Each round was administered through the Google Form survey platform. Questionnaires were sent with a maximum of 3 days of allowed delay for the response and with a gap of 15 days between the response collection and the next round; one week of time to send the feedback was given to the coordinators. Due to the COVID-19 emergency, days between the second and the third rounds have been prolonged to 90 .

Figure 1 reports a detailed scheme of how the Delphi rounds and iteration were organized and operated.

In the first round (round 1), the original statements formulated by the writing committee were evaluated by the expert panel using a Likert scale ranging from 1 to 4, whereas additional suggestions (statements that did not reach a complete agreement in the pre-round phase) were voted using numeric range threshold as reported in Table 1 . In round 1, the possibility to propose additional suggestions and add free comments was also given to the members of the expert panel.

Free comments suggested by the expert panel and collected in the first round were then directly considered together with the additional suggestions by the writing committee which have reached an appropriate consensus during round $1(\geq 15-20$ votes) in the formulation of round 2 items. Conversely, the additional suggestions proposed by the expert panel in round 1 and the additional suggestions by the writing committee, which have reached an intermediate consensus during round 1 (10-14 votes), were re-tabled for the vote in round 2 . In round 2 and round 3 , an agreement scale ranging from 1 to 10 was adopted.

\section{Statistical analysis}

The Delphi rounds were conducted using a Likert scale with 4 points in round 1 and 9 points in round 2 and round 3. Data were analyzed in terms of consensus, agreement, and stability in all rounds with the exception for round 1, where a Likert scale with 4 points was used in order to facilitate the lecture for the experts and let them concentrate on the contents. Consensus is intended as a degree of accordance between experts and it was expressed as the interquartile range (IQR) whereas agreement is intended as the degree of accordance

Table 1 Thresholds established to evaluate the items during round iteration.

\begin{tabular}{lllll}
\hline Fixed threshold & & & & Action \\
\cline { 1 - 3 } & Round 1 & Round 2 & Round 3 & \\
\hline Item & $\geq 80 \%$ Likert 4/4 & Median $\geq 8 \mathrm{IQR} \leq 2$ & Median $\geq 8 \mathrm{IQR} \leq 2$ & Preserve the item \\
& $<80 \%$ Likert $4 / 4$ & Median $<8 \mathrm{IQR}>2$ & Median $<8 \mathrm{IQR}>2$ & Reformulate the item \\
Additional suggestion & $\geq 15 / 20$ & $\geq 15 / 20$ & $\geq 15 / 20$ & Include into the item \\
& $10-14 / 20$ & $10-14 / 20$ & $\backslash$ & Propose in the next round with literature support \\
& $<10 / 20$ & $<10 / 20$ & $<15 / 20$ & Remove \\
\hline
\end{tabular}




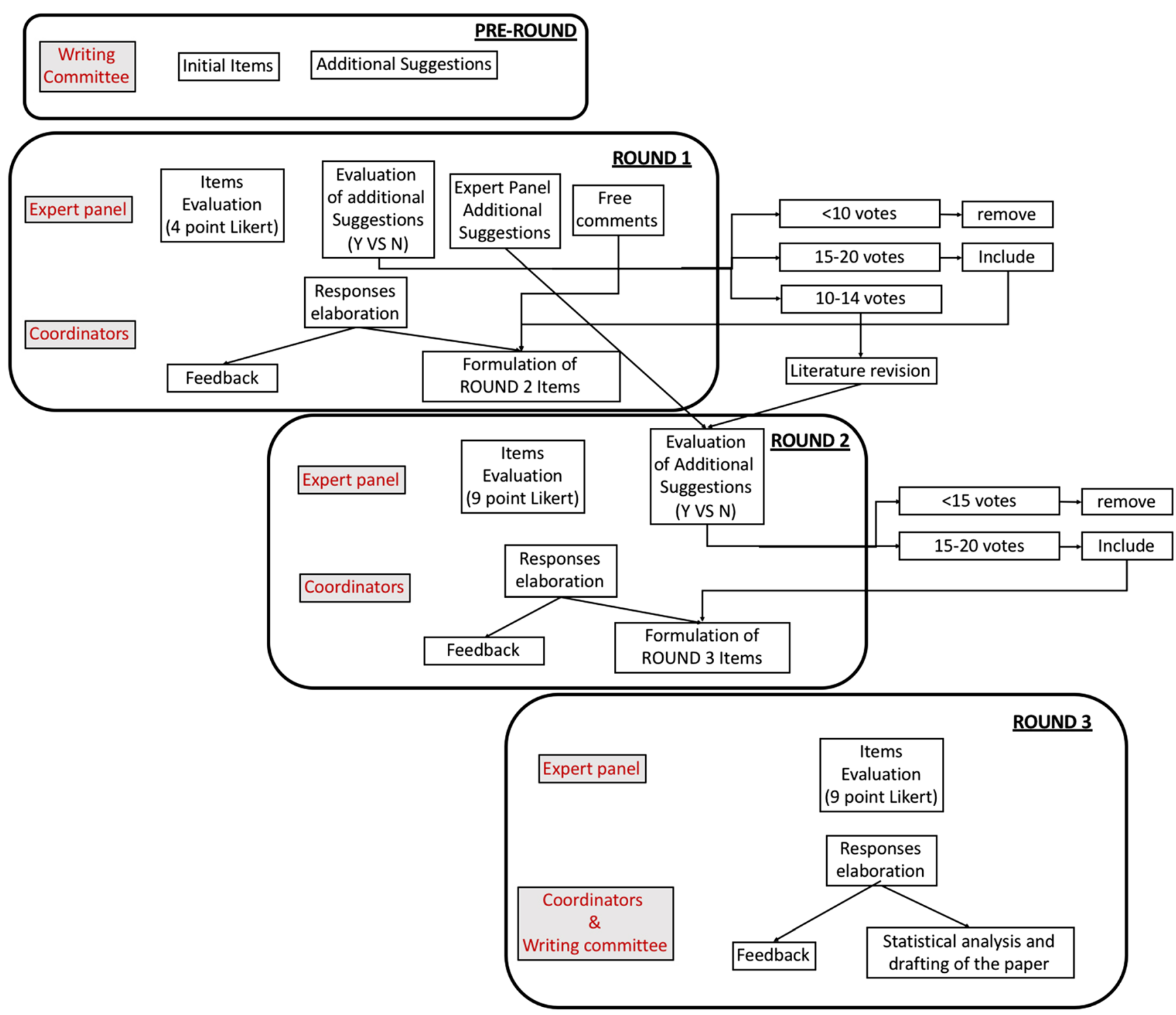

Figure 1 Delphi Iterations. The figure reports a scheme of how the Delphi rounds were organized and operated. $Y=$ yes; $N=$ not

with statements, expressed in terms of the median. Finally, the stability, intended as the coherence of subjects' responses in successive rounds, was evaluated through a Wilcoxon matched-pairs signed-rank test (significant if $p<0.05$ meaning there is no stability).

\section{Results}

The response rate from the expert panel in round 1 and round 2 resulted to be $100 \%$, with the participation of 10 out of 10 radiologists and 10 out of 10 oncological surgeons. Nevertheless, in round 3, the response diminished to $95 \%$, with 9 out of 10 oncological surgeons responding. Figure 2 summarized the number of items that reach the fixed threshold used during the Delphi iteration for each round.

\section{Round 1}

During round 1,10 out of 24 items did not reach the threshold to be promoted as unchanged in the next round $(80 \%$ of the rates of the expert panel equal to 4 on the Likert scale).

The item "clinical referral" in all the three sections of the CT report (staging, restaging, and follow-up) did not reach the threshold of $\geq 80 \%$ Likert $4 / 4$ in round 1 and were considered not understandable by the expert panel in free comments; for that reason, during the data elaboration and item reformulation for round 2 , the item was split into two different sub-items in each section of the CT report, the former listing the "clinical referrals" to be included in the final version of the report and the latter reporting "clinical information" the radiologist should know before performing the CT examination (Table 2). 
24 items

$\begin{array}{ll}14 \text { items } & \geq 80 \% \text { Likert } 4 \\ 10 \text { items } & <80 \% \text { Likert } 4\end{array}$

\begin{tabular}{|c|c|}
\hline 20/21 items & $\begin{array}{l}\text { agreement } \geq 8 \quad \text { ROUND 2 } \\
\text { consensus } \geq 2\end{array}$ \\
\hline 3 items & $\begin{array}{c}\text { agreement and consensus } \\
\text { not evaluated }\end{array}$ \\
\hline & ROUND 3 \\
\hline 23/24 items & $\begin{array}{l}\text { agreement } \geq 8 \\
\text { consensus } \geq 2\end{array}$ \\
\hline $19 / 20$ items & stability $p>0,05$ \\
\hline 4 items & $\begin{array}{c}\text { stability } \\
\text { not evaluated }\end{array}$ \\
\hline
\end{tabular}

Figure 2 The number of items that reached fixed threshold during rounds iteration

\section{Round 2}

Since the clinical referral items for each section of the CT report (3 items: staging, restaging, and follow-up) were reformulated for round 2 , it was not possible to evaluate its agreement and consensus during this round. Round 2 was then composed of 21 items to be voted. Among these 21 items, only the "conclusion" item of the follow-up section of the CT report did not reach the threshold (agreement: median $\geq$ 8 and consensus: IQR $\leq 2$ ).

Regarding the "clinical referrals" items, for each section of the CT report, a very large cluster of statements were proposed to the expert panel during round 2, asking them to vote the appropriateness in order to properly incorporate each of them into the sub-items "clinical referrals" to be included in the final version of the report and the latter reporting "clinical information" the radiologist should know before performing the CT examination, excluding from "clinical referrals" those which did not reach at least 15 out of 20 approvals/votes.

\section{Round 3}

Tables 2, 3, 4, and 5 reported the final items to be included in the CT report and the result of Delphi iteration in terms of agreement, consensus, and stability.

Round 3 was composed of 24 items to be voted. It was not possible to evaluate the stability for 4 items ("clinical referrals" items for each section of the CT report and "conclusion" item for the follow-up section) since they were reformulated in round 2 .

Two items did not reach the fixed threshold: (1) the item "conclusion" in the staging section did not reach the goal for

Table 2 Clinical information the radiologist should know before performing the CT examination

\begin{tabular}{|c|c|c|c|}
\hline Item & $\begin{array}{l}\text { Information the radiologist should know but should } \\
\text { not be necessarily included in the report }\end{array}$ & Agreement (median) & Consensus (IQR) \\
\hline Staging & $\begin{array}{l}\text { - Histotype of the tumor, if provided by the biopsy (Lauren / WHO); } \\
\text { - Relevant clinical symptoms (bleeding, occlusion, etc.); } \\
\text { - Previous cancer history, if present, and related stage of disease; } \\
\text { - If the patient suffers from one of the following pathologies: FAP, } \\
\text { Li-Fraumeni, HNPCC, Peutz-Jeghers, HDGC; } \\
\text { - Cardiovascular comorbidity }\end{array}$ & 8 & 2 \\
\hline Restaging & $\begin{array}{l}\text { - Number of chemotherapy cycles and date of the last cycle; } \\
\text { - Extraparietal extension of the primary tumor if documented through } \\
\text { laparoscopy; } \\
\text { - Type of laparoscopic procedure performed (e.g., retrocavity opening, } \\
\text { peritoneal biopsies); } \\
\text { - Results of any peritoneal biopsies; } \\
\text { - Results of peritoneal lavage, if performed; }\end{array}$ & 8 & 1,5 \\
\hline Follow-up & $\begin{array}{l}\text { - Histotype of the neoplasm (Lauren / WHO) } \\
\text { - TRG according to Becker and/or Mandard; } \\
\text { - Any post-surgical complications; } \\
\text { - Results of peritoneal lavage; } \\
\text { - Basal tumor markers (CA 19.9, CEA) } \\
\text { - Tumor markers on the date of the follow-up examination } \\
\text { - Residual tumor indicator (especially if R0); } \\
\text { - Previous/other oncological pathology and its stage; } \\
\text { - If cholecystectomy and/or splenectomy is performed; } \\
\text { - If omentectomy is performed; } \\
\text { - If peritonectomy and/or HIPEC is performed; }\end{array}$ & 9 & 1 \\
\hline
\end{tabular}


Table 3 Final version of the items and results for the staging section of the CT report

\begin{tabular}{|c|c|c|c|c|}
\hline Item & Information to be included in the radiological report & $\begin{array}{l}\text { Agreement } \\
\text { (median) }\end{array}$ & $\begin{array}{l}\text { Consensus } \\
\text { (IQR) }\end{array}$ & $\begin{array}{l}\text { Stability } \\
\text { (p) }\end{array}$ \\
\hline Clinical referral & $\begin{array}{l}\text { - Site (upper/middle/ lower 1/3, lesser/greater curvature, anterior /posterior wall); } \\
\text {-Features (stenosing, ulcerated, perforated) and staging of the neoplasm obtained by } \\
\text { endoscopy; } \\
\text { - Possible previous partial gastrectomy and/or other types of gastric surgery and/or } \\
\text { endoscopic resections; } \\
\text { The radiologist should point out in this section if clinical information provided were not } \\
\text { adequate. }\end{array}$ & 9 & 1.5 & I \\
\hline Technique & $\begin{array}{l}\text { - Specify if correct gastric distension has been performed, the modality of distension (air } \\
\text { or water, and the reasons for any failure of distension; } \\
\text { - Specify if gastric hypotonization has been carried out; } \\
\text { - Report any adverse reaction to intravenous contrast media (in that case, report the } \\
\text { contrast agent administered); } \\
\text { - Report the presence of any motion artifacts or problems that occurred during CT } \\
\text { examination; } \\
\text { - Report if dual-energy technique (DECT) was used. }\end{array}$ & 9 & $\mathbf{0}$ & 0.705 \\
\hline \multicolumn{5}{|c|}{ The } \\
\hline T parameter & $\begin{array}{l}\text { - Site (lesser/greater curve, upper/middle/lower } 1 / 3 \text {, anterior/posterior wall); } \\
\text { - Features (stenosing, ulcerated, perforated); } \\
\text { - Gastric wall infiltration ( } \leq \mathrm{T} 2 \text { or } \geq \mathrm{T} 3 \text { ); } \\
\text { - Distance from the esophago-gastric junction or possible esophageal infiltration (the } \\
\text { involvement of the esophagus should be expressed in mm from the hiatus); } \\
\text { - Possible infiltration of perigastric organs/structures (pancreas, liver, mesocolon, etc.); } \\
\text { - Possible duodenal infiltration; } \\
\text { - Maximum dimension (D-max) of the lesion [23]; } \\
\text { - Anatomical anomalies (hiatal hernia, gastric migration); } \\
\text { - Possible infiltration of vascular structures. }\end{array}$ & 9 & $\mathbf{0}$ & 0.480 \\
\hline $\mathbf{N}$ parameter & $\begin{array}{l}\text { - Presence/absence of LN involvement (N0 vs N +); } \\
\text { - Site of metastatic LN (stations number according to JGCA or anatomical description } \\
\text { according to AJCC) [25,43]; } \\
\text { - Short diameter of the largest metastatic LN for each station; } \\
\text { - Possible adhesion/infiltration of anatomical structures by LNs (e.g., pancreatic capsule, } \\
\text { spleen, hepatic artery, etc.); } \\
\text { - In case of confluent lymphadenopathy, report it and indicate the maximum diameter of } \\
\text { the package. }\end{array}$ & 9 & 1 & 0.376 \\
\hline $\begin{array}{l}\text { Peritoneal } \\
\text { carcinomatosis }\end{array}$ & $\begin{array}{l}\text { - Presence/absence of ascites; } \\
\text { - Presence/absence of peritoneal carcinomatosis; } \\
\text { - Specify if supra- or sub-mesocolic involvement; } \\
\text { - Specify if nodules in the omental bursa; } \\
\text { - Report the diameter of the largest nodule (up to 2); } \\
\text { - Specify whether bowel loop involvement and/or infiltration of the mesentery root; } \\
\text { - Presence/absence of Krukenberg tumor; } \\
\text { - Presence/absence of "omental cake". }\end{array}$ & 9 & $\mathbf{0}$ & 0.480 \\
\hline Liver metastases & $\begin{array}{l}\text { - Presence/absence of liver metastases; } \\
\text { - Number: indicate if unique, or number up to max 3, or if }>3 \text { indicate "multiple"; } \\
\text { - Site (liver segments involved); } \\
\text { - Maximum diameter (single measure in mm) of largest metastases (up to } 2 \text { in } \\
\text { accordance with RECIST1.1) [44]; } \\
\text { - Specify the infiltration of a major intrahepatic vessel (portal vein, IVC, suprahepatic veins); } \\
\text { - Describe any hepatopathy (liver cirrhosis, signs of portal hypertension). }\end{array}$ & 9 & $\mathbf{0}$ & 0.429 \\
\hline Other metastases & $\begin{array}{l}\text { - Site (lung, bone, distant lymph nodes ...); } \\
\text { - Number: indicate if unique, or number up to max 3, or if }>3 \text { indicate "multiple"; } \\
\text { - Size: indicate the Dmax of the largest lesion for each involved organ; } \\
\text { - Report non-measurable lesions (lymphangitis, pleural effusion ...). }\end{array}$ & 9 & $\mathbf{0}$ & 0.075 \\
\hline $\begin{array}{l}\text { Useful information } \\
\text { for the surgeon }\end{array}$ & $\begin{array}{l}\text { - Vascular anomalies; } \\
\text { - Presence of incisional hernias. }\end{array}$ & 9 & 1 & 0.185 \\
\hline Conclusions/advice & $\begin{array}{l}\text { - The radiologist should provide a clinical-radiological staging (cTNM (CT): T } \\
\text { expressed as }</=\mathrm{T} 2 \text { or }>/=\mathrm{T} 3 \text { or } \mathrm{T} 4 \mathrm{~b}, \mathrm{~N} \text { expressed as } \mathrm{N} 0 \text { or } \mathrm{N}+, \mathrm{M} \text { expressed as } \\
\mathrm{M} 0 \text { or } \mathrm{M}+\text { ); } \\
\text { - The radiologist should recommend the discussion of the clinical case at the } \\
\text { multidisciplinary group. }\end{array}$ & 8 & 2.5 & 0.812 \\
\hline
\end{tabular}


Table 4 Final version of the items and results for the restaging section of the CT report

\begin{tabular}{|c|c|c|c|c|}
\hline Statement & Information to be included in the report & $\begin{array}{l}\text { Agreement } \\
\text { (median) }\end{array}$ & $\begin{array}{l}\text { Consensus } \\
\text { (IQR) }\end{array}$ & $\begin{array}{l}\text { Stability } \\
\text { (p) }\end{array}$ \\
\hline Clinical referrals & $\begin{array}{l}\text { - Possible extraparietal extension of the primary lesion at laparoscopy, if performed; site } \\
\text { (upper/middle/ lower } 1 / 3 \text {, lesser/greater curvature, anterior /posterior wall); } \\
\text { - Specify the date of the CT examination used for the comparison. } \\
\text { The radiologist should point out in the radiological report if clinical information provided is not } \\
\text { adequate. }\end{array}$ & 9 & 1 & I \\
\hline Technique & $\begin{array}{l}\text { - Specify if correct gastric distension has been performed, the modality of distension (air or } \\
\text { water), and the reasons for any failure to distension; } \\
\text {-Specify if gastric hypotonization has been carried out; } \\
\text { - Report any adverse reaction (in that case, report the contrast agent administered); } \\
\text { - Report the presence of any motion artifacts or problems that occurred during CT examination; } \\
\text { - Report if dual-energy technique (DECT) was used. }\end{array}$ & 9 & $\mathbf{0}$ & 0.257 \\
\hline \multicolumn{5}{|c|}{ 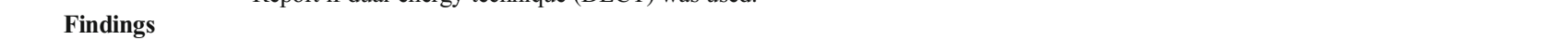 } \\
\hline T parameter & $\begin{array}{l}\text { - Site (upper/middle/lower 1/3, lesser/greater curvature, anterior/posterior wall); } \\
\text { - Report the lesion D-max specifying the percentage reduction compared to the staging CT); } \\
\text { - Gastric wall infiltration ( } \leq \mathrm{T} 2 \text { or } \geq \mathrm{T} 3 \text { ) and if there have been any changes compared with the } \\
\text { staging CT (downstaging/upstaging); } \\
\text { - Distance from the esophago-gastric junction or possible esophageal infiltration (the } \\
\text { involvement of the esophagus should be expressed in mm from the hiatus); } \\
\text { - Possible infiltration of perigastric organs/structures (pancreas, liver, mesocolon ...); } \\
\text { - Possible duodenal infiltration; } \\
\text { - Features of the lesion (stenosing, ulcerated, perforated); }\end{array}$ & 9 & $\mathbf{0}$ & 0.465 \\
\hline N parameter & $\begin{array}{l}\text { - Specify if N0 or N+; } \\
\text { - If N+ specify the short axis of the largest metastatic LN for each station (or any confluent LNs) } \\
\text { compared with the previous one (e.g., st.6: } 6 \mathrm{~mm} \text { ex } 10 \mathrm{~mm} \text { ); } \\
\text { - Site of metastatic LN (stations number according to JGCA or anatomical description } \\
\text { according to AJCC) } \\
\text { - Possible adhesion/infiltration of anatomical structures. }\end{array}$ & 9 & 0,5 & 0,046 \\
\hline $\begin{array}{l}\text { Peritoneal } \\
\text { carcinomatosis }\end{array}$ & $\begin{array}{l}\text { - Appearance/disappearance or increase/reduction of ascites, also to suggest paracentesis; } \\
\text { - Appearance/disappearance or increase/reduction of peritoneal carcinomatosis; } \\
\text { - Specify if supra- or sub-mesocolic infiltration; } \\
\text { - Specify involvement of bowel loops and mesentery (especially mesenteric root infiltration). } \\
\text { - Absence/presence of omental cake }\end{array}$ & 9 & $\mathbf{0}$ & 0.564 \\
\hline Liver metastases & $\begin{array}{l}\text { - Specify presence/absence of liver metastases; } \\
\text { - Number: report the increase/stability or reduction in the number of liver metastases; specify if } \\
\text { unique, or number up to 3, or if }>3 \text { indicate "multiple"; } \\
\text { - Site (liver segments involved); } \\
\text { - Dimension: indicate increase/stability or reduction of liver dimensional metastases, reporting } \\
\text { the maximum diameter (single measurement in mm) of largest lesions (up to 2), chosen as a } \\
\text { target in the staging report, also getting the measures of comparison with the previous one } \\
\text { (e.g., mts. 1: } 5 \text { ex } 10 \mathrm{~mm} \text {; mts. } 2: 3 \mathrm{ex} 8 \mathrm{~mm} \text { ) or maximum diameter of max } 2 \text { larger } \\
\text { metastases identified in the restaging CT, always reporting comparison with the previous } \\
\text { one, if the targets have not been previously identified. } \\
\text { - Specify whether contact/infiltration of a large intrahepatic vessel (portal vein, IVC, } \\
\text { supra-hepatic veins), also reporting the comparison with the staging CT; }\end{array}$ & 9 & $\mathbf{0}$ & 0.705 \\
\hline Other metastases & $\begin{array}{l}\text { - Specify whether disease progression/stability or response to therapy; } \\
\text { - Site (lung, bone ...); } \\
\text { - Number: report the increase/stability or reduction in number for each site; specify if unique, or } \\
\text { number up to max 3, or if }>3 \text { indicate "multiple"; } \\
\text { - Dimension: indicate increase/stability or reduction of dimensional metastases for each site, } \\
\text { reporting the maximum diameter (single measure in mm) of the metastasis/es chosen as a } \\
\text { target in the staging report (up to } 2 \text { per organ in accordance with RECIST 1.1), getting the } \\
\text { comparison with the previous one (eg. mts } 1: 5 \text { ex } 10 \mathrm{~mm} \text {; mts } 2: 3 \text { ex } 8 \mathrm{~mm} \text { ) or maximum } \\
\text { diameter of max } 2 \text { larger metastases identified in the restaging CT, always reporting } \\
\text { comparison with the previous one (e.g. mts } 1: 5 \text { ex } 10 \mathrm{~mm} \text {; mts } 2: 3 \text { ex } 8 \mathrm{~mm} \text { ), if the targets } \\
\text { are not previously identified. } \\
\text { - Specify if there are non-measurable lesions (lymphangitis, pleural effusion ...); }\end{array}$ & 9 & $\mathbf{0}$ & 0.084 \\
\hline $\begin{array}{l}\text { Useful information } \\
\text { for the surgeon }\end{array}$ & $\begin{array}{l}\text { - Vascular anomalies; } \\
\text { - Presence of incisional hernias. }\end{array}$ & 9 & 1 & 0.162 \\
\hline Conclusions/advice & $\begin{array}{l}\text { - The radiologist should provide post-treatment clinical-radiological staging (ycTNM [25] } \\
\text { (CT): T expressed as } \leq \mathrm{T} 2 \text { or } \geq \mathrm{T} 3, \mathrm{~N} \text { expressed as } \mathrm{N} 0 \text { or } \mathrm{N}+, \mathrm{M} \text { expressed as } \mathrm{M} 0 \text { or } \mathrm{M}+\text { ) } \\
\text { - The radiologist should recommend the discussion of the clinical case at the multidisciplinary } \\
\text { group. }\end{array}$ & 8 & 2 & 0.464 \\
\hline
\end{tabular}


Table 5 Final version of the items and results for the follow up section

\begin{tabular}{|c|c|c|c|c|}
\hline Statement & Information to be included in the report & $\begin{array}{l}\text { Agreement } \\
\text { (median) }\end{array}$ & $\begin{array}{l}\text { Consensus } \\
\text { (IQR) }\end{array}$ & $\begin{array}{l}\text { Stability } \\
\text { (p) }\end{array}$ \\
\hline Clinical referrals & $\begin{array}{l}\text { - pTNM (or ypTNM); } \\
\text { - Surgery performed: total vs sub-total gastrectomy; type of reconstruction (Billroth II vs } \\
\text { Roux), type of lymphadenectomy (D1, D2 or D2 plus, D3); } \\
\text { The radiologist should point out in the radiological report if clinical information provided } \\
\text { is not adequate. }\end{array}$ & 9 & 1.5 & l \\
\hline Technique & $\begin{array}{l}\text { - Specify if correct distension of the residual stomach or anastomosis has been performed, } \\
\text { the modality of distension (air or water), and the reasons for any failure to distension; } \\
\text { - Specify if gastric hypotonization has been carried out; } \\
\text { - Report any adverse reaction to intravenous contrast media (in that case, report the } \\
\text { contrast agent administered); } \\
\text { - Report the presence of any movement artifact or problem that occurred during the CT } \\
\text { examination; } \\
\text { - Report if examination performed with dual-energy technique. } \\
\text { - Report if important changes in the protocol compared to the reference examination. }\end{array}$ & 9 & $\mathbf{0}$ & 0.272 \\
\hline $\begin{array}{l}\text { Loco-regional } \\
\text { relapse }\end{array}$ & $\begin{array}{l}\text { - Site of the relapse (gastric bed, duodenal stump, anastomosis/perianastomotic area); } \\
\text { - Dimension; } \\
\text { - Contact with/infiltration of anatomical and vascular structures. }\end{array}$ & 9 & $\mathbf{0}$ & 0.655 \\
\hline Lymphatic relapse & $\begin{array}{l}\text { - Site of the recurrence (according to the JGCA number stations or anatomical description } \\
\text { according to AJCC); } \\
\text { - Number of LN involved (expressed in } \geq 3 \text { or } \geq 7 \text { ); } \\
\text { - Dimension (short diameter of the largest LN for each station). }\end{array}$ & 9 & 1 & 0.398 \\
\hline Distant relapse & $\begin{array}{l}\text { - Site; } \\
\text { - Number for each anatomical site: indicate if unique, or number up to max } 3 \text {, or if }>3 \\
\text { indicate "multiple"; } \\
\text { - Size: indicate the maximum diameter of the largest lesion for each involved organ; } \\
\text { - If there are skeletal lesions, specify lesions at risk of fracture/vertebral canal invasion; } \\
\text { - If liver involvement, specify segments and contact/infiltration of major vascular } \\
\text { structures; } \\
\text { - Specify the presence of ascites; } \\
\text { - Specify the presence of peritoneal carcinomatosis; }\end{array}$ & 9 & $\mathbf{0}$ & 0.317 \\
\hline Conclusions/advice & $\begin{array}{l}\text { - Report if disease recurrence is present; } \\
\text { - Indicate possible accessible anatomical sites for histological sample/confirmation. }\end{array}$ & 8 & 2 & I \\
\hline
\end{tabular}

consensus (IQR > 2). (2) The item "lymph node status" in the restaging section did not reach enough stability between round 2 and round $3(p<0.05)$.

The "conclusions" item of each section of the CT report resulted to be the item with the lowest degree of agreement and consensus (although it resulted sufficient in the majority of cases); in more detail, the surgical oncologists had a lower degree of accordance than radiologists in each of the three sections (staging $7 \pm 3$ vs $8 \pm 1$, restaging $7 \pm 3$ vs $8 \pm 1$, follow up $8 \pm 3$ vs $8 \pm 1$ ).

\section{Discussion}

GC is a severe disease, often diagnosed in an advanced stage in Western countries, which can benefit from an aggressive and multimodal treatment that requires a complex decisionmaking process, the latter largely driven by imaging and in particular by CT [28].
At the time of staging, imaging is aimed at splitting patients who can benefit from an up-front surgery from those who need a chemotherapy treatment whether it is for neoadjuvant, conversion, or palliative purposes. Anyway, imaging is also crucial at the time of re-staging, after neoadjuvant or conversion therapy, in order to anticipate yc-staging in a pre-surgical time, thus giving the possibility to steer the patient's subsequent treatment from a surgical approach alone to a possible multimodality approach [28-31].

Considering the complexity of GC patient management and in the era of personalized therapy, it is essential that the patient is addressed to a diagnostic and therapeutic work-up in a multidisciplinary team (MDT) through a collaboration between the radiologist and the medical and surgical oncologists. A prerequisite for this purpose is the expertise of medical staff related to the many aspects and issues of GC [4].

An international survey by the European Society of Oncologic Imaging revealed that most radiologists attend MDT, but less than half of them review clinical images in advance due to time constraints. The time required for a radiologist 
to review the images of a case reported by him/herself is different from that necessary to review a case reported by another colleague, or even multiple examinations performed in different hospitals. Furthermore, sometimes they are obligated to write an additional report which could influence the clinical decisionmaking of patients, independently of whether his/her opinion agrees or not with the previous report [32].

For this reason, a structured radiological report, shared between radiologists and clinicians (surgical oncologists), may reduce the radiologist's time review and could improve the communication between the radiologist and the other members of MDT.

It is also crucial to note that the written radiological report is part of the patient's permanent health record, and, as also stated by the European Society of Radiology (ESR), "the appropriate construction, clarity, and clinical focus of a radiological report are essential to high-quality patient care" [26].

Moreover, the dissemination of the structured report is increasing in oncology since many advantages due to the standardization of contents that allows comparing CT examination performed in different diagnostic times by different radiologists and hospitals and the realization of a CT report that contains all the necessary answers to the questions of the clinicians at different diagnostic times (staging, restaging, and follow-up).

According to the ESR good practice for radiological reporting, the broad categories of a structured report can be summarized as (a) clinical referral, (b) technique, (c) findings, (d) conclusion, and (e) advice, each of which is adequately described in the same document [26].

Regarding the category "clinical referral," in round number 1 of our survey, there was no agreement about the clinical referral to be provided by clinicians to radiologists and those that radiologists have to include into the CT report on each section (staging, restaging, and follow-up); thus, the clinical information to be included into the report was separated from clinical information to provide to radiologists, choosing only the clinical referral deemed necessary (essential) and promoting these as clinical referral to be included into the report, thus easily accessible by all members of MDT [32].

Regarding the category "technique," in GC, an appropriate methodology of CT exam execution is at least as important as a correct description of the findings. The distention and hypotonization of the gastric wall, together with the use of a late arterial contrast-enhanced phase, high $\mathrm{kVp}$ and $\mathrm{mA}$, and a thin slice thickness, are essential technical requirements to improve the accuracy of T staging [14]. In the same way, an equilibrium phase, better if performed using the dual-energy technique, a new technology that is rapidly emerging in oncology, will dig up a PC without ascites or allow differential diagnosis between PC and fibrosis after treatment (Fig. 3) [33-38]. Both radiologists and surgical oncologists considered it essential to include the technique in the $\mathrm{CT}$ report with a very good agreement in all rounds for all sections of the structured report.
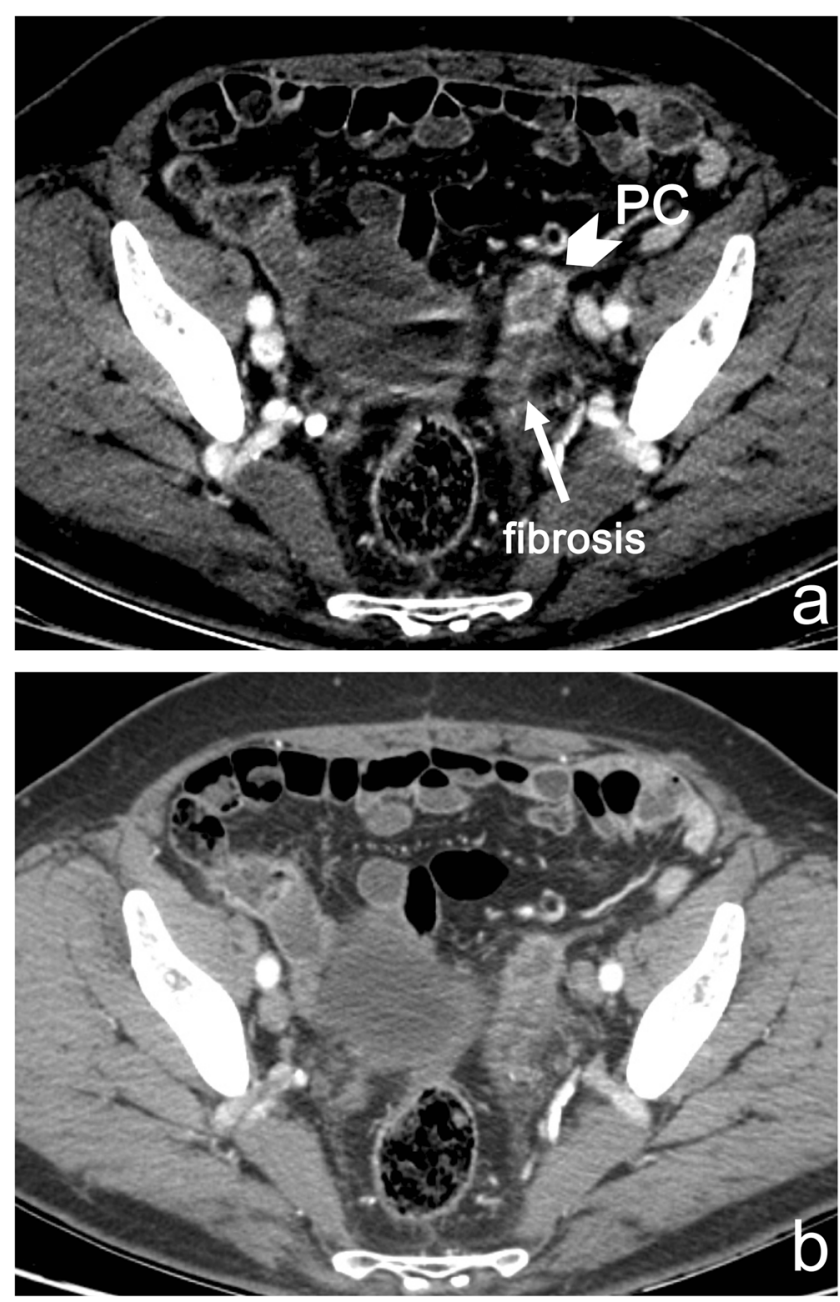

Figure 3 a, b Peritoneal recurrence in a 54-year-old man with diffuse GC, who underwent cytoreductive surgery and HIPEC. Monoenergetic images at $40 \mathrm{keV}$ (a) show a conspicuous vascularization of a nodule of PC (arrowhead) in the left external iliac site, next to an area of fibrosis (arrow) and without ascites. It is not possible to distinguish between PC and fibrosis at standard $140 \mathrm{kVp}$ images (b)

The category "findings" in staging and restaging sections was subdivided into 6 sub-categories to better organize the CT report: T-parameter, N-parameter, peritoneal carcinomatosis, liver metastases, other metastases, and useful information for surgeons. Conversely, the categories conclusion and advice have been merged into a single category that has not reached the agreement (Tables 3, 4, and 5). In particular, in round number 1, surgeons did not accept that radiologists gave suggestions about the patient's subsequent management or their therapeutic approach. The debate on this issue is based on the fact that if a suggestion about treatment type is explicated in the CT report and the surgeon makes a different choice (for example dictated by the patient's comorbidity or poor compliance not fully known to the radiologist), the disagreement can lead to medico-legal problems in case of a negative outcome for that patient. Therefore, it is desirable that the main decisions are always taken by the MDT. Controversy has been solved in 
round number 2: "the radiologist should promote/recommend the discussion of the clinical case in a MDT" is the shared advise for staging and restaging sections of the CT report, whereas in the follow-up section of the CT report, the radiologist should suggest the most feasible type and site for biopsy in case a disease relapse is suspected [39-42].

Some reflections about the sustainability of the CT report have been carried on in the initial phase of the study by the coordinators. In particular, the proper balance between the scientific and practicability of the report has been carefully considered during the process of drawing the CT report itself. Anyway, the formulation of a structured report in GC patients, shared by surgical and medical oncologists and radiologists, is extremely useful in order to obtain an appropriate, clearer, and focused CT report essential to high-quality patient care. Moreover, such kind of report provides a dedicated checklist of findings to be mentioned at different diagnostic times (staging, restaging, and follow-up) of GC assessment. This dedicated checklist is extremely useful to experts as to inexperienced radiologists/ residents who are approaching this disease, in order to write a more appropriate CT report avoiding the exclusion of key radiological information useful for multidisciplinary decision-making.

In conclusion, the complex decision-making process that underlies choices in GC treatment, largely driven by CT, well lends itself as a model for a CT report shared among experts. In this sense and in view of personalized medicine, there are advantages to push ahead a more uniform style and content of radiological report, with consequent benefits for the patients and the physicians involved in their treatment, as well as to make audit, research, and teaching easier.

Acknowledgements The authors thank Prof. Fabio Ferretti for performing statistical analysis.

Funding The authors state that this work has not received any funding.

\section{Declarations}

Guarantor The scientific guarantor of this publication is Prof. Maria Antonietta Mazzei.

Conflict of interest The authors of this manuscript declare no relationships with any companies whose products or services may be related to the subject matter of the article.

Statistics and biometry Prof. Fabio Ferretti kindly provided statistical advice for this manuscript.

Informed consent Written informed consent was not required for this study because it is a Delphi questionnaire.

Ethical approval Institutional Review Board approval was not required because the study is a Delphi questionnaire.
Methodology

- multicentre Delphi study

\section{References}

1. Smyth EC, Nilsson M, Grabsch HI, van Grieken NC, Lordick F (2020) Gastric cancer. Lancet 396:635-648

2. Cancer Genome Atlas Research Network (2014) Comprehensive molecular characterization of gastric adenocarcinoma. Nature 513: 202-209

3. Smyth EC, Verheij M, Allum W et al (2016) Gastric cancer: ESMO Clinical Practice Guidelines for diagnosis, treatment and follow-up. Ann Oncol 27(suppl 5):v38-v49

4. Allum W, Lordick F, Alsina M et al (2018) ECCO essential requirements for quality cancer care: Oesophageal and gastric cancer. Crit Rev Oncol Hematol 122:179-193

5. Millor M, Bartolomé P, Pons MJ et al (2019) Whole-body computed tomography: a new point of view in a hospital check-up unit? Our experience in 6516 patients. Radiol Med 124:1199-1211

6. Petralia G, Padhani AR, Pricolo P et al (2019) Whole-body magnetic resonance imaging (WB-MRI) in oncology: recommendations and key uses. Radiol Med 124:218-233

7. Pimentel-Nunes P, Dinis-Ribeiro M, Ponchon T et al (2015) Endoscopic submucosal dissection: European society of gastrointestinal endoscopy (ESGE) guideline. Endoscopy 47:829-854

8. Cunningham D, Allum WH, Stenning SP et al (2006) Perioperative chemotherapy versus surgery alone for resectable gastroesophageal cancer. N Engl J Med 355:11-20

9. Schuhmacher C, Gretschel S, Lordick F et al (2010) Neoadjuvant chemotherapy compared with surgery alone for locally advanced cancer of the stomach and cardia: European Organisation for Research and Treatment of Cancer randomized trial 40954. J Clin Oncol 28:5210-5218

10. Ychou M, Boige V, Pignon JP et al (2011) Perioperative chemotherapy compared with surgery alone for resectable gastroesophageal adenocarcinoma: an FNCLCC and FFCD multicenter phase III trial. J Clin Oncol 29:1715-1721

11. Kang Y-K, Yook JH, Park Y-K et al (2019) Phase III randomized study of neoadjuvant chemotherapy (CT) with docetaxel(D), oxaliplatin(O) and S-1(S) (DOS) followed by surgery and adjuvant S-1, vs surgery and adjuvant S-1, for resectable advanced gastric cancer (GC) (PRODIGY). Ann Oncol. https://doi.org/10.1093/ annonc/mdz394.032

12. Ji J, Shen L, Li Z et al (2019) Perioperative chemotherapy of oxaliplatin combined with s-1 (SOX) versus postoperative chemotherapy of SOX or oxaliplatin with capecitabine (XELOX) in locally advanced gastric adenocarcinoma with D2 gastrectomy: a randomized phase III trial (RESOLVE Trial). Ann Oncol. https:// doi.org/10.1093/annonc/mdz394.033

13. Al-Batran SE, Homann N, Pauligk C et al (2019) Perioperative chemotherapy with fluorouracil plus leucovorin, oxaliplatin, and docetaxel versus fluorouracil or capecitabine plus cisplatin and epirubicin for locally advanced, resectable gastric or gastrooesophageal junction adenocarcinoma (FLOT4): a randomised, phase 2/3 trial. Lancet 393:1948-1957

14. De Manzoni G, Marrelli D, Baiocchi GL et al (2017) The Italian Research Group for Gastric Cancer (GIRCG) guidelines for gastric cancer staging and treatment: 2015. Gastric Cancer 20:20-30

15. Zhu Z, Gong Y, Xu H (2020) Neoadjuvant therapy strategies for advanced gastric cancer: current innovations and future challenges. Chronic Dis Transl Med 6:147-157

16. Sun W, Yan L (2016) Gastric cancer: current and evolving treatment landscape. Chin J Cancer 31(1):35-83 
17. Bonnot PE, Piessen G, Kepenekian V et al (2019) Cytoreductive surgery with or without hyperthermic intraperitoneal chemotherapy for gastric cancer with peritoneal metastases (CYTO-CHIP study): a propensity score analysis. J Clin Oncol 37:2028-2040

18. Zhang HW, Yang JJ, Zheng JY, Sun L, Yang XW, Li GC (2019) Postoperative intraperitoneal hyperthermic perfusion improve survival for advanced gastric cancer. Medicine (Baltimore) 98:e16598

19. Beom SH, Choi YY, Baek SE et al (2018) Multidisciplinary treatment for patients with stage IV gastric cancer: the role of conversion surgery following chemotherapy. BMC Cancer 18:1116

20. Zhang F, Huang X, Song Y et al (2019) Conversion surgery for stage IV gastric cancer. Front Oncol 9:1158

21. Solaini L, Ministrini S, Bencivenga M et al (2019) Conversion gastrectomy for stage IV unresectable gastric cancer: a GIRCG retrospective cohort study. Gastric Cancer 22:1285-1293

22. Marrelli D, Mazzei MA, Pedrazzani C et al (2011) High accuracy of multislices computed tomography (MSCT) for para-aortic lymph node metastases from gastric cancer: a prospective single-center study. Ann Surg Oncol 18(8):2265-2272

23. Mazzei MA, Cioffi Squitieri N, Vindigni C et al (2020) Gastrointestinal stromal tumors (GIST): a proposal of a "CT-based predictive model of Miettinen index" in predicting the risk of malignancy. Abdom Radiol 45(10):2989-2996

24. Larson DB (2018) Strategies for implementing a standardized structured radiology reporting program. Radiographics. 38:1705-1716

25. Amin MB, Edge S, Greene F, Byrd DR et al (2018) AJCC cancer staging manual, 8th edn. Springer International Publishing

26. Good practice for radiological reporting (2011) Guidelines from the European Society of Radiology (ESR). Insights Imag 2:93-96

27. Trevelyan EG, Robinson N (2015) Delphi methodology in health research: how to do it? Eur J Integr Med 7:423-428

28. Mazzei MA, Bagnacci G, Gentili F et al (2018) Gastric cancer maximum tumour diameter reduction rate at $\mathrm{CT}$ examination as a radiological index for predicting histopathological regression after neoadjuvant treatment: a multicentre GIRCG study. Gastroenterol Res Pract 2018:1794524

29. Mazzei MA, Nardone V, Di Giacomo L et al (2018) The role of delta radiomics in gastric cancer. Quant Imag Med Surg 8(7):719721

30. Ma M, Di Giacomo L, Bagnacci G et al (2021) Delta-radiomics and response to neoadjuvant treatment in locally advanced gastric cancer - a multicenter study of GIRCG (Italian Research Group for Gastric Cancer). Quant Imaging Med Surg. 11(6):2376-2387

31. Messina C, Bignone R, Bruno A et al (2020) Diffusion-weighted imaging in oncology: an update. Cancers (Basel) 12(6):1493
32. Kane B, Luz S, O'Briain DS, McDermott R (2007) Multidisciplinary team meetings and their impact on workflow in radiology and pathology departments. BMC Med 13:5-15

33. Shi B, Lin H, Zhang M, Lu W, Qu Y, Zhang H (2018) Gene regulation and targeted therapy in gastric cancer peritoneal metastasis: radiological findings from dual energy $\mathrm{CT}$ and PET/CT. J Vis Exp 22(131):56526

34. Darras KE, Clark SJ, Kang H et al (2019) Virtual monoenergetic reconstruction of contrast-enhanced CT scans of the abdomen and pelvis at $40 \mathrm{keV}$ improves the detection of peritoneal metastatic deposits. Abdom Radiol (NY) 44(2):422-428

35. Volterrani L, Gentili F, Fausto A et al (2020) Dual-energy CT for locoregional staging of breast cancer: preliminary results. AJR Am J Roentgenol 214(3):707-714

36. Gentili F, Guerrini S, Mazzei FG et al (2020) Dual energy CT in gland tumors: a comprehensive narrative review and differential diagnosis. Gland Surg 9(6):2269-2282

37. Agostini A, Borgheresi A, Mari A et al (2019) Dual-energy CT: theoretical principles and clinical applications. Radiol Med 124(12):1281-1295

38. Cicero G, Ascenti G, Albrecht MH et al (2020) Extra-abdominal dual-energy CT applications: a comprehensive overview. Radiol Med 125(4):384-397

39. Cornacchia S, Errico R, Balzano RF et al (2019) Medical radiological procedures: which information would be chosen for the report? Radiol Med 124(8):783-793

40. Ross T, Pawa N (2020) The multi-disciplinary team - who is liable when things go wrong? Eur J Surg Oncol 46(1):95-97

41. Sidhom MA, Poulsen MG (2006) Multidisciplinary care in oncology: medicolegal implications of group decisions. Lancet Oncol 7(11):951-954

42. Neri E, Gabelloni M, Bäuerle T et al (2021) Involvement of radiologists in oncologic multidisciplinary team meetings: an international survey by the European Society of Oncologic Imaging. Eur Radiol 31:983-991

43. Japanese Gastric Cancer Association (2021) Japanese gastric cancer treatment guidelines 2018 (5th edition). Gastric Cancer 24:1-21

44. Eisenhauer EA, Therasse P, Bogaerts J et al (2009) New response evaluation criteria in solid tumours: revised RECIST guideline (version 1.1). Eur J Cancer 45(2):228-247

Publisher's note Springer Nature remains neutral with regard to jurisdictional claims in published maps and institutional affiliations.

\section{Affiliations}

Maria Antonietta Mazzei ${ }^{1,2} \cdot$ Giulio Bagnacci $^{1,2} \cdot$ Francesco Gentili $^{2,3}$ (D) $\cdot$ lacopo Capitoni ${ }^{1} \cdot$ Gianni Mura $^{4}$. Daniele Marrelli ${ }^{5}$ - Roberto Petrioli ${ }^{6}$. Luca Brunese ${ }^{7,8}$. Salvatore Cappabianca ${ }^{9,8}$ - Marco Catarci ${ }^{10}$. Maurizio Degiuli ${ }^{11}$. Giovanni De Manzoni ${ }^{12}$. Marco De Prizio ${ }^{4}$. Annibale Donini ${ }^{13}$ • Uberto Fumagalli Romario ${ }^{14}$. Luigi Funicelli ${ }^{14,2,8}$. Andrea Laghi ${ }^{15,16}$. Giuseppe Minetti ${ }^{17,2} \cdot$ Paolo Morgagni $^{18}$. Enrico Petrella ${ }^{19} \cdot$ Frida Pittiani $^{20,2}$. Stefano Rausei ${ }^{21} \cdot$ Laura Romanini $^{22} \cdot$ Riccardo Rosati $^{23}$ - Amato Antonio Stabile lanora ${ }^{24} \cdot$ Guido A. M. Tiberio ${ }^{25}$. Luca Volterrani $^{1,8} \cdot$ Franco Roviello $^{5} \cdot$ Roberto Grassi $^{9,26}$

1 Department of Medical, Surgical and Neuro Sciences, University of Siena and Department of Radiological Sciences, Unit of Diagnostic Imaging, Azienda Ospedaliera Universitaria Senese, Siena, Italy

2 SIRM, Italian College of Computed Tomography, Italian Society of Medical and Interventional Radiology, Milan, Italy
3 Unit of Diagnostic Imaging, Azienda Ospedaliera Universitaria Senese, Siena, Italy

4 Department of Surgery, Division of General Surgery, Arezzo Hospital, Arezzo, Italy 
5 Department of Medicine, Surgery and Neuroscience, Unit of General Surgery and Surgical Oncology, University of Siena, Siena, Italy

6 Department of Oncology, Unit of Medical Oncology, Azienda Ospedaliera Universitaria Senese, Siena, Italy

7 Department of Medicine and Health Sciences, University of Molise, Campobasso, Italy

8 SIRM, Italian College of Oncology, Italian Society of Medical and Interventional Radiology, Milan, Italy

9 Division of Radiology, University of Campania Luigi Vanvitelli, Naples, Italy

10 FACS; UOC Chirurgia Generale; Ospedale Sandro Pertini - ASL Roma 2, Roma, Italy

11 Surgical Oncology and Digestive Surgery Unit, Department of Oncology, University of Turin; San Luigi University Hospital, Orbassano, Italy

12 Unit of General and Upper GI Surgery, University of Verona, Verona, Italy

13 Department of Surgery and Biomedical Sciences, University of Perugia, Perugia, Italy

14 Digestive Surgery, IEO European Institute of Oncology - IRCCS, Milan, Italy

15 Department of Surgical and Medical Sciences and Translational Medicine, Sapienza University of Rome - Sant'Andrea University Hospital, Rome, Italy
16 SIRM, Italian College of Gastroenterology, Italian Society of Medical and Interventional Radiology, Milan, Italy

17 Radiology Department, Ospedale Policlinico San Martino, IRCCS per L'Oncologia e le Neuroscienze, Genoa, Italy

18 General and Oncologic Surgery, Morgagni-Pierantoni Hospital, Forlì, Italy

19 Radiology Unit, Morgagni-Pierantoni Hospital, AUSL Romagna, Forlì, Italy

20 Department of Radiology, ASST Spedali Civili Brescia, Brescia, Italy

21 Department of Surgery, ASST Valle Olona, Gallarate, Varese, Italy

22 Department of Radiology, ASST Cremona, Cremona, Italy

23 Endocrine Unit, Department of Surgery, IRCCS San Raffaele Scientific Institute, Milan, Italy

24 Interdisciplinary Department of Medicine, Section of Radiology and Radiation Oncology, University of Bari, Bari, Italy

25 Surgical Unit, Department of Experimental and Clinical Sciences, University of Brescia, Brescia, Italy

26 SIRM Foundation, Italian Society of Medical and Interventional Radiology, Milan, Italy 